\title{
SYNOPSIS
}

News

$\bullet$

Analysis

- Practice

Global Health

\section{WHO's call for international pandemic action unheeded}

Despite the World Health Organization's plea that wealthy nations should help developing countries finance preparations for an impending influenza pandemic, two-thirds of the world's population will likely face the first wave of a virulent new strain without significant help.

Although many developed countries, including Canada (CMA7 2005;172 [9]:1167), have planned surveillance, vaccine production and mass distribution of antiviral medications for their own populations, most impoverished countries face the prospect of a pandemic without such infrastructure or international aid.

Few influenza experts take issue with the WHO's call to arms, but fewer see it as realistic. "Other than the usual WHO altruism, I don't think there's a whole lot of teeth to what they're doing," said Dr. Fred Aoki, a University of Manitoba research scientist and one of Canada's top influenza experts. "Most countries are struggling to get their own houses in order."

Dr. Klaus Stohr, coordinator of the WHO's global influenza program, told CMAJ that developed countries have a responsibility to support pandemic preparedness. "I don't mean ... developed countries should pump money in for stockpiles in developing countries. That may actually be wrong, unless it's done in a comprehensive way. But supporting developing countries with their pandemic preparedness programs means the country would know how much it would take to move ahead.
That definitely makes sense."

The gap between those nations with influenza plans and the have-nots is staggering. The UK, for example, is spending $\$ 700$ million over 2 years to stockpile antiviral drugs. According to WHO, this is roughly 10 times the entire annual health budget of Vietnam. In Cambodia, the annual budget for a campaign to encourage citizens to report suspected cases of Avian influenza is about \$3000. A UN conference in Ho Chi Minh City in February concluded that East Asia, the front line in the fight against H5N1 Avian influenza, requires $\$ 123$ million just to establish a network of labs to monitor and control human infections.

The WHO has argued the lack of resources for surveillance and testing in developing countries, especially those countries believed to be the likely source of the next pandemic, could mean delays in identifying the new strain, giving it time to spread.

But if resources were available to blanket a source country with antiviral drugs, Aoki says the explosiveness of a new strain would likely make it virtually impossible to contain, especially in regions with little or no public health system. By the time a new strain is identified, it will have spread to multiple points around the world. It would be virtually impossible to produce enough antiviral medication to saturate countries likely to serve as ground zero, Aoki says.

Dr. Frank Plummer, director general for the Centre for Infectious Disease Prevention and

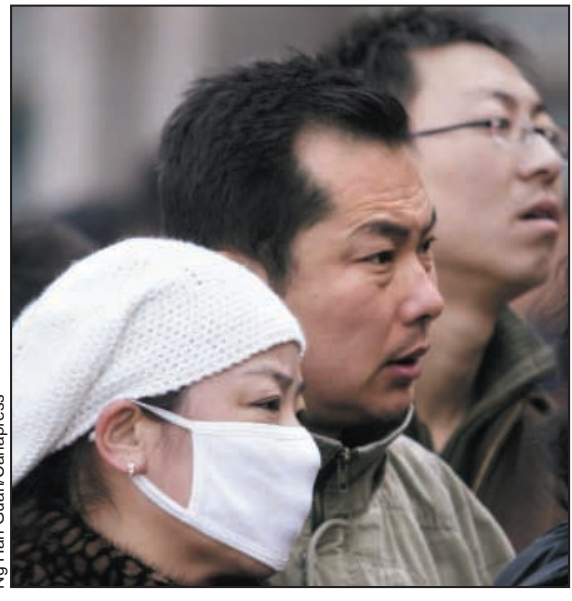

Resources at the probable ground zero for an influenza pandemic are minimal.

Control at the Public Health Agency of Canada, says some efforts are being made to help developing countries. The World Bank is mobilizing a plan to fund influenza programs in developing countries, and several nations including Canada have sent small teams of scientists to countries such as Vietnam to help build surveillance and testing networks, Plummer says.

An influenza pandemic could have a devastating impact on countries already afflicted by war, hunger and disease, most notably HIV/AIDS, Plummer says. These conditions have left entire populations vulnerable to the rapid and relatively easy spread of an influenza virus.

"It's hard to tell how bad it could get in developing countries," Plummer says. "But you can be confident it will be much worse than we see. How much worse is difficult to say." - Dan Lett, Winnipeg 